\title{
Environmental citizenship behavior (the effect of environmental sensitivity, knowledge of ecology, personal investment in environmental issue, locus of control towards students' environmental citizenship behavior)
}

\author{
Agus Priadi $^{*}{ }^{*}$, Erian Fatria ${ }^{1}$, Nadiroh $^{1}$, Dahlia Sarkawi $^{2}$, and Anggi Oktaviani ${ }^{3}$ \\ ${ }^{1}$ Environmental Education Department, Universitas Negeri Jakarta, 13220 Jakarta Timur, Indonesia \\ ${ }^{2}$ Office Administration Dept., Universitas Bina Sarana Informatika, 17411 Jakarta Timur, Indonesia \\ ${ }^{3}$ Information System Dept., STMIK Nusa Mandiri,10450 Jakarta Pusat, Indonesia
}

\begin{abstract}
Environmental problems that continue to occur to this day has become a serious threat to the international world. Despite numerous research and investigation against the environmental problems continue to be done, but the solutions offered have not been fully able to cope with environmental problems. It is important that we should examine and change is our daily behaviors as a wise society to the environment. This article aims to review some research articles related to Environmental Citizenship Behaviors. Review this article based on the flowchart "Environmental Citizenship Behavior" developed by Hungerford \& Volk in 1990. The research method used is survey with a causal approach and characterized by a data analysis technique using path analysis. The nature of the research used to test both direct and indirect effect among variables. In the framework of the flowchart was developed the variables in the Entry Level, the Ownership, and Empowerment of influential directly and indirectly towards the Environmental Citizenship Behavior to the environment. Based on the findings, it could be concluded that all of these entry level variables, ownership variables, and empowerment variables have direct and indirect effect towards environmental citizenship behavior.
\end{abstract}

\section{Introduction}

Over the last several years, individuals would involve themselves in the SDGs to gain adequate knowledge about SDGs itself. Of course, there is the need to understand the detail purpose and target of SDGs. However, it is also very important to understand is the logic behind SDGs, as illustrated by the shift of the MDGs to the SDGs, also how the relationship among the components of the economic, social and environmental. SDGs embraced nested sustainability model, which means that the economy is part of the social,

${ }^{1}$ Corresponding author: agus.agp@bsi.ac.id 
and the social is part of the environment. Conveying regard economic, social, and environmental pillars or thinking mode in triple bottom line surely is not right, and deny the basic logic where SDGs madeEcological concerns are increasingly construed in a moralized fashion in the public arena, pressing companies to advance the environmental cause in a more responsive and holistic manner [1,2]. Accompanying this trend, research on the civic attitudes and citizenship behaviors of individuals in organizations $[3,4]$ has emphasized the need to consider the natural environment as a stakeholder in its own right. There is indeed a growing sense that "the moral actions of the firm interact with the moral concerns of students in influencing their behaviors within the organizational context" [5]. On this basis, a developing body of research has explored how both individual and organizational determinants influence the discretionary involvement of students in the management of a company's environmental impact [6-8].

Although these studies have advanced our knowledge in this area, this line of research is still relatively underdeveloped, and the social-psychological processes leading individuals to engage in informal environmental initiatives in the work context are not fully comprehended [9]. The importance of understanding how students go about initiating innovative and spontaneous behaviors directed at environmental improvement has been highlighted in the literature.

Subordination and other structural aspects of organizations do not simply create by fiat widespread student commitment in environmental affairs. As organizations increase their environmental citizenship behaviors efforts, the ongoing challenge, therefore, is to translate official organizational policies into decentralized and emergent individual initiatives [7, 10]. Otherwise, programs will be poorly integrated, innovations will be lost, the technology underutilized, and problems will not be resolved timely and effectively. Through their discretionary actions, students are thus instrumental in contributing to corporate environmental performance. They help address the diversity and complexity of environmental issues, and compensate for the inherent limitations of formal management practices, systems, and technologies [3].

For that reason, the purpose of this study was to gain a better understanding of the social-psychological mechanisms underlying innovative and spontaneous student acts directed at environmental improvement in the work context-otherwise known as "environmental citizenship behaviors" [3,4]. To examine student willingness to engage in citizenship behaviors toward the environment, we developed a path analysis model that integrated people's discretionary sense of commitment to environmental concerns in the workplace. The model involved hypotheses at both the within-person and between-person levels (see Fig. 2), and was tested in two steps [11, 12].

By exploring a model of workplace environmental citizenship that examines how individual environmental commitment arises or is sustained in organizations, this study contributes to the corporate greening and organizational behavior literature by extending recent theoretical [13] and empirical research [14]. Considering, defining, and developing the concept of student environmental commitment is an important endeavor. Indeed, although this theme has been a long-standing, recurring leitmotif in the corporate greening literature [15], most research tends to speak of it in an implicit, general, and elusive way. Similarly, while it has long been recognized in the organizational behavior literature that students can develop workplace commitments that transcend organizational boundaries [16, 17], research on commitments to socially responsible practices is still in its infancy and deserves greater attention $[18,19]$. The remainder of the paper is organized as follows. In the next section, the background is presented and the research hypotheses are developed. The research method, analytical procedure, and results are then reported. Last, the study findings and their implications are discussed in light of the corporate greening and organizational behavior literature. 
This research uses major entry level variable namely Environmental Sensitivity, and minor entry level variable namely Knowledge of ecology. For the major ownership variable namely Personal investment in issues and the environment, and for the major empowerment variable namely Locus of Control. All of these variables have a causal relationship towards the Environmental Citizenship Behavior that can be described through the following hypothetical model as follows.

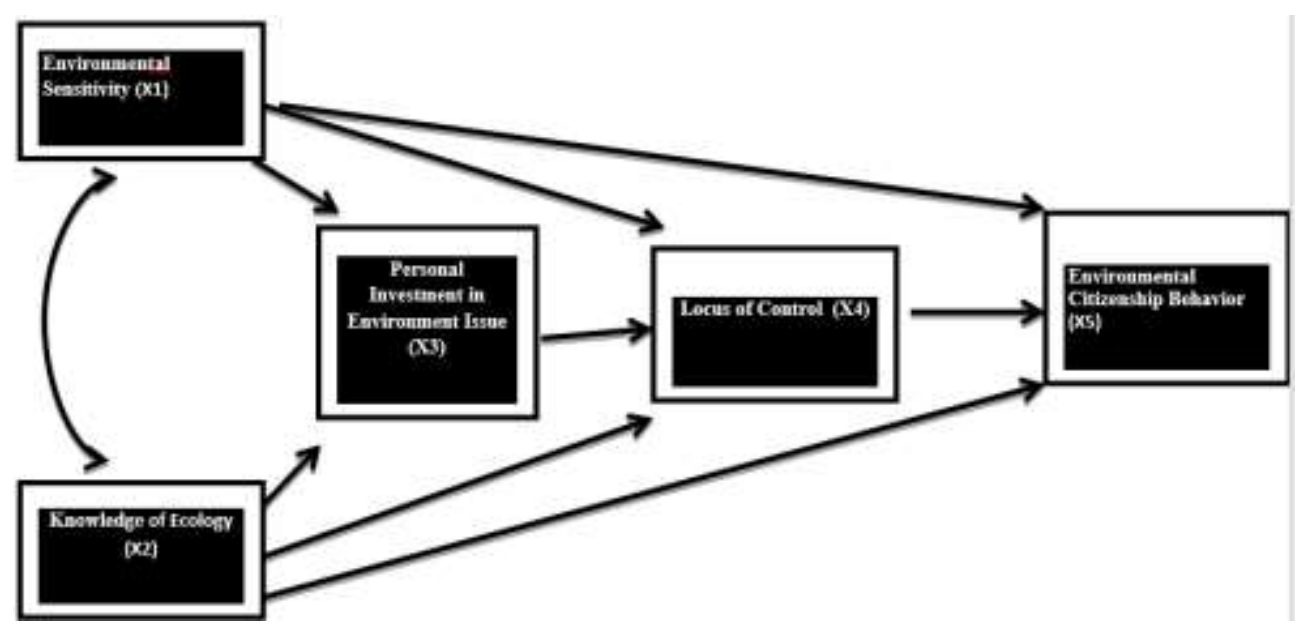

Fig. 2. Research hypothesis model.

\section{Material and methods}

The research method used is survey method with a causal approach is characterized by a data analysis technique using path analysis. The nature of the research used to test both direct and indirect effect between variables. Facts studied to see the effect of exogenous and endogenous: (1) environmental sensitivity $\left(\mathrm{X}_{1}\right)$, (2) knowledge of ecology $\left(\mathrm{X}_{2}\right)$, (3) personal investment in environment issue $\left(\mathrm{X}_{3}\right)$, (4) locus of control $\left(\mathrm{X}_{4}\right)$, and (5) environmental citizenship behavior $\left(\mathrm{X}_{5}\right)$.

The sample taking in this research uses multistage random sampling technique. The population in this study is students from ABA BSI Jakarta, 132 students as samples. There were five instruments for measuring, Environmental Citizenship Behavior (22 items), Environmental Sensitivity (28 items), Knowledge of Ecology (31 items), , Personal Investment in Environmental Issue (24 items), and Locus of Control (27 items). Data normality test used Liliefors by Kolmogorov Smirnov (K-S) formulation and homogenity test used by Bartlett formulation. Data was analyzed by descriptive statistical analysis, inferential statistics for linearity test and path analysis.

Statistical tests were used to test the hypothesis of the research : 1) direct effect of Environmental Sensitivity (X1) against Environmental Citizenship Behavior (X5); 2) direct effect of Knowledge of Ecology (X2) against Environmental Citizenship Behavior (X5); 3) direct effect of Locus of Control (X 4) against Environmental Citizenship Behavior (X5); 4) direct effect of Environmental Sensitivity (X1) against Personal Investment in Environment Issue (X3); 5) direct effect of Knowledge of Ecology (X2) against the Personal Investment in Environment Issue (X3), 6) direct effect of Environmental Sensitivity (X1) against Locus of Control (X4); 7) direct effect of Knowledge of Ecology (X2) against Locus of Control (X4); 8) direct effect of Personal Investment in Environment 
Issue (X3) against the Locus of Control (X4); 9) indirect effect of Environmental Sensitivity (X1) against Environmental Citizenship Behavior (X5) through Locus of Control (X4); 10) indirect effect of Knowledge of Ecology (X2) against Environmental Citizenship Behavior (X5) through Locus of Control (X4).

\section{Result and discussion}

Based on causal effect is calculated using path coefficient (pij). Based on the path diagram below, there are eight path coefficients, namely $\mathrm{p}_{13}, \mathrm{p}_{14}, \mathrm{p}_{23}, \mathrm{p}_{24}, \mathrm{p}_{34}, \mathrm{p}_{1 \mathrm{y}}, \mathrm{p}_{2 \mathrm{y}}, \mathrm{p}_{4 \mathrm{y}}$.

Table 1. Path coefficient, direct effect, indirect effect, total effect.

\begin{tabular}{|c|c|c|c|c|c|c|c|c|}
\hline \multirow{3}{*}{ Path } & \multicolumn{5}{|c|}{ Causal Effect } & \multirow{3}{*}{$\begin{array}{l}\text { Total } \\
\text { Effect }\end{array}$} & \multirow{3}{*}{ t-cal } & \multirow{3}{*}{$\begin{array}{l}\text { t-tab } \\
\alpha .05\end{array}$} \\
\hline & \multirow{2}{*}{$\begin{array}{l}\text { Direct } \\
\text { Effect }\end{array}$} & \multicolumn{3}{|c|}{ Intervening } & \multirow{2}{*}{$\begin{array}{c}\text { Indirect } \\
\text { Effect }\end{array}$} & & & \\
\hline & & $\mathrm{X}_{3}$ & $\mathrm{X}_{4}$ & $\mathrm{X}_{3}$ and $\mathrm{X}_{4}$ & & & & \\
\hline $\mathrm{X}_{1} \mathrm{X}_{5}$ & .332 & - & .063 & .017 & .233 & .565 & $6.283^{*}$ & 1.97 \\
\hline$\overline{X_{1} X_{3}}$ & .182 & - & - & - & - & .182 & $2.117^{*}$ & 1.97 \\
\hline $\mathrm{X}_{3} \mathrm{X}_{5}$ & - & - & .096 & - & .096 & .096 & $3.591 *$ & 1.97 \\
\hline $\mathrm{X}_{2} \mathrm{X}_{5}$ & .278 & - & .121 & .019 & .14 & .418 & $5.039 *$ & 1.97 \\
\hline $\mathrm{X}_{2} \mathrm{X}_{4}$ & .308 & .048 & - & - & .048 & .356 & $3.884^{*}$ & 1.97 \\
\hline $\mathrm{X}_{4} \mathrm{X}_{5}$ & .392 & - & - & - & - & .392 & $6.756^{*}$ & 1.97 \\
\hline$\overline{X_{3} X_{4}}$ & .245 & - & - & - & - & .245 & $3.069 *$ & 1.97 \\
\hline $\mathrm{X}_{1} \mathrm{X}_{4}$ & .162 & .044 & - & - & .044 & .206 & $2.116^{*}$ & 1.97 \\
\hline $\mathrm{X}_{2} \mathrm{X}_{3}$ & .196 & - & - & - & - & .196 & $2.288^{*}$ & 1.97 \\
\hline
\end{tabular}

The results revealed that students' environmental citizenship behavior significantly affected directly by environmental sensitivity, knowledge of ecology and locus of control. It was also significantly affected indirectly by personal investment in environment issue. While locus of control was significantly affected directly by environmental sensitivity, knowledge of ecology and personal investment in environment issue. On the other hand, personal investment in environment issue was significantly affected directly by environmental sensitivity and knowledge of ecology.

From the results of testing hypothesis can be concluded that there is a direct positive effect of environmental sensitivity to students' environmental citizenship behavior. This implies that environmental sensitivity has a positive direct effect on students' environmental citizenship behavior. The results of this study are consistent with the opinion of $[1,2]$ state that "ecological concerns are increasingly construed in a moralized fashion in the public arena, pressing companies to advance the environmental cause in a more responsive and holistic manner". Revealing about research on civic attitudes and citizenship behaviors of individuals in organizations is supported by [3, 4]. It is indeed will grow sense of moral actions which interact with moral concerns of students in persuading their behaviors.

Meanwhile [4] state that knowledge of ecology is influenced by the success or failure of the management which inheres their willingness to support change and responsibility for the ecological impact.

The importance of understanding how students go about initiating innovative and spontaneous behaviors directed at environmental improvement has been highlighted in the literature could be seen from their social psychological process which leads individuals to involve their environmental initiatives during the work context as said by [9]. 
By implementing the model of workplace environmental citizenship that determines how each person of environmental commitment emerges or is backed up in institutions, this research gives the corporate organizational behavior literature by exaggerating latest theory as it is said by [13] and empirical research said by [14]. Referring, defining, and elaborating the concept of student environmental commitment is an important endeavor. Indeed, although this theme has been a long-standing, most research tends to speak in an implicit, general, and elusive way. Similarly, while it has long been acknowledged in the organizational behavior literature that students can develop workplace commitments that transcend organizational boundaries said by $[16,17]$, as it is said from $[18,19]$ that research on commitments to socially responsible practices is still in its infancy and deserves greater attention.

\section{Conclusion}

Based on the results of research and discussion have been parsed then retrieved the findings as follows: 1) Environmental Sensitivity positively and directly affects toward Environmental Citizenship Behavior, which means that when the higher environmental sensitivity of a person has, the better environmental citizenship behavior will be; 2) Knowledge of ecology positively and directly affects against Environmental Citizenship Behavior, which means that the higher of a person's knowledge related to ecology has, the better Environmental Citizenship Behavior will be; 3) Locus of Control positively and directly affects toward Environmental Citizenship Behavior, which means that the more internal locus of control of a person has, the better Environmental Citizenship Behavior will be; 4) Environmental Sensitivity positively and directly affects against Personal Investment in Environment Issue, it means that the higher the Environmental Sensitivity of a person has, the better its investments on the environment will be; 5) Knowledge of Ecology positively and directly affects against a Personal Investment in the Environment Issue, it means that the higher of a person's knowledge related to ecology has, the better of its investments on the environment will be; 6) Environmental Sensitivity positively and directly affects toward the Locus of Control, it means that the higher the Environmental Sensitivity of a person has, the more internal Locus of Control will be; 7) Knowledge of Ecology positively and directly affects toward the Locus of Control, which means that the higher of a person's Knowledge related to ecology has, the more internal locus of control will be; 8) Personal Investment in Environment Issue positively and directly affects toward Locus of Control, it means that the better of one's Investments on the environment has, the more internal Locus of Control will be; 9) Environmental Sensitivity positively and indirectly affects toward Environmental Citizenship Behavior through Locus of Control which means that the higher of Environmental Sensitivity of a person has, the better his/her Environmental Citizenship Behavior If it is mediated by locus of control internally. 10) Knowledge of Ecology positively and indirectly affects toward Environmental Citizenship Behavior through Locus of Control which means that the higher knowledge of a person related to ecology he/she has, the better of his/her environmental citizenship behavior if it is mediated by locus of control internally.

\section{Acknowledgements}

I would like to convey my gratitude to all my friends who helped me support my research particularly to my institution. 


\section{References}

1. P. Bansal, \& Roth, K. Acad. of Man. J. 43, 4, 717-736 (2000)

2. S. Kumar \& A. Pandey. The Sci-Wo J. 1-16 (2013)

3. O. Boiral. J. of Bus. Ethics 87, 221-236 (2009)

4. B.F. Daily, J.W. Bishop, \& N. Govindarajulu. J. Bus. \& Soc. 48, 243-256 (2009)

5. H.C. Anderson, P.T. Hodges, X.M. Aguilera, 1. Missana, P.E. Moylan. J. Histochem. Cytochem. 48 1493-1502 (2000)

6. L.M. Andersson and T.S. Bateman. Acad. of Man. J. 43, 4, 548-570 (2000)

7. E. Lamm, J. Tosti-Kharas, \& E.G. Williams. J. Group \& Org. Man. 38, 163-197 (2013)

8. E. Temminck, K. Mearns, \& L. Fruhen. J. Bus. Strat. and Env. 24, 402-412 (2015)

9. D.S. Ones \& S. Dilchert. J. of Indus. and Org. Psy. 5, 444-466 (2012)

10. O. Boiral \& P. Paille. J. of Bus. Ethics 109, 431-445 (2012)

11. L.J. Williams \& S.E. Anderson. J. of Man. 17, 601-617 (2003)

12. D.T. Wegener \& L.R. Fabrigar, Exploratory Factor Analysis: Understanding Statistics. (Oxford University Press, New York, 2012)

13. J. Mesmer- Magnus, C. Viwsevaran, \& B.M. Wiernik, The Role of Commitment in Bridging the Gap between Organizational Sustainability and Environmental Sustainability. In S.E. Jackson, D.S. Ones, \& S. Dilchert (Eds), Managing Human Resources for Environmental Sustainability (Jossey-Bass, San Fransisco, CA, 2012)

14. L. Perez-Lombard, J. Ortiz, \& R. Gonzalez. J. of Energy. and Building (2009)

15. Paul, Keogh, Douglas, and M.J. Polonsky. J. Org. Change Man. 11, 1, 38-49 (1998)

16. C. Morrow and C.J. McElroy. J. of Bus. Research 26, 1-2 (1993)

17. A.E. Reichers. Acad. of Man. Review 10, 465-476 (1985)

18. C. Jane \& E. Rafael. Bus. \& Ethics J. 16, 19-33 (2007)

19. D.D. Bingham. Amer. J. of Human Bio. 25, 6, 733-742 (2013) 